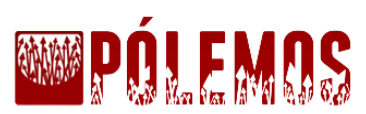

\section{A POLÊMICA DO VÉU ISLÂMICO NO ESTADO SECULAR MODERNO SOB A ÓTICA DO DIREITO À DIFERENÇA}

\begin{abstract}
Abhner Youssif Mota Arabi
RESUMO

O presente artigo parte da proibição do uso de burca e niqab em ambientes públicos na França para discutir temas concernentes ao Estado Moderno e aos limites de suas ações tendo em vista seu caráter de secularidade, bem como os direitos subjetivos das minorias político-legislativas. Trata também esse trabalho dos reflexos de tais problemas na democracia contemporânea, vendo no real reconhecimento do diferente o caminho para a efetiva inclusão.
\end{abstract}

Palavras-chave: Democracia; Religião; Véu.

Abstract: This article starts from the prohibition of the use of burqa and niqab in public places in France in order to discuss issues that concern to the modern secular state and also to the limits of its action in the context of the subjective rights of political minorities. This work also brings the consequences of this problematic point in contemporary democracy, and considers that the real acknowledgment of differences is the only way to achieve de effective inclusion.

Key words: Democracy; Religion; Veil.

\section{Introdução}

A universalização de direitos fundamentais entre as diferentes culturas e realidades sociais constitui hoje um dos maiores desafios da teoria do Direito. Em nome de direitos universais e intrínsecos a qualquer ser humano, os direitos humanos, tem-se feito um grande esforço para a implementação muitas vezes forçada, e inclusive com uso de forças militares, de certos direitos em sociedades onde se diz predominar regimes não democráticos, muitos deles pautados em idealizações religiosas e culturais, como a maioria das sociedades islâmicas e orientais, por exemplo. Tal choque cultural tem gerado debates em áreas diversas, e impasses de difícil solução pelas vias do direito internacional; e tem se mostrado não só na interferência do Ocidente, em nome da universalização dos direitos humanos, em países orientais, mas também dentro da própria população de um país: dado o grande pluralismo da sociedade contemporânea, o embate "Oriente x Ocidente" se revela também dentro de uma mesma nacionalidade. 
Tais problemas têm sua dimensão estendida pelas fortes ondas migratórias que hoje existem, o que fortifica ainda mais o aspecto pluriétnico e pluricultural no interior do território dos Estados, evidenciando a questão de como tais diferenças, evitando a degeneração de tais pluralismos em conflitos diversos ou sua transformação em movimentos fundamentalistas. Tem-se um grande exemplo disso na sociedade francesa pela proibição do uso em locais públicos de certas vestes típicas da tradição cultural islâmica.

A França possui uma das maiores comunidades islâmicas da Europa e, ainda assim, foi o primeiro país do continente a abordar a polêmica questão do uso do véu islâmico. Tal antiga questão foi objeto legislativo em 2004: com base em argumentos como o de integração da população islâmica com os demais, e no chamado direito à identidade da pessoa, proibiu-se, inicialmente, o uso de véus ou qualquer outro símbolo religioso nas escolas estatais francesas. Em tal ocasião, as divergências se revelaram, mas o maior motivo de debates e desentendimentos sobre o assunto veio em setembro de 2010: pela quase unanimidade (246 votos a um) o Senado francês aprovou projeto de lei (que já havia sido aprovado anteriormente pela Câmara dos Deputados e foi ratificado posteriormente pelo Conselho de Estado) que proíbe o uso dos chamados "véus integrais" (burca e niqab) ${ }^{1}$ em ambientes públicos. A lei previu um prazo de seis meses para a adaptação voluntária das mulheres, tendo vigência só a partir de então, e proibia a "ocultação do rosto em espaços públicos"2.

Tal polêmica ressurgiu recentemente com a ocorrência das primeiras condenações judiciais: no final de setembro de 2011 o Tribunal de Police de Meaux condenou duas mulheres ao pagamento de multas por terem sido presas usando as peças proibidas.

Esta posição do estado francês tem provocado diversas reações na sociedade civil, sejam elas contrárias ou favoráveis a tal situação: do mesmo modo que surgem estímulos à desobediência civil e organizações como a Association Touche Pas à Ma Constitution ${ }^{3}$,

1 A burca, típica de países como o Afeganistão e Paquistão, é um tipo de véu que cobre todo o corpo da mulher muçulmana que a usa, inclusive rosto e olhos, tendo apenas uma rede que possibilita a visão do mundo externo. Já o niqab é considerado a versão árabe da burca: também cobre todo o corpo, deixando, entretanto, os olhos expostos.

2 LOI $n^{\circ}$ 2010-1192 du 11 octobre 2010 interdisant la dissimulation du visage dans l'espace public, disponível em www.legifrance.gouv.fr/affichTexte.do?cidTexte=JORFTEXT000022911670\&dateTexte= 3 A Associação Não Toque Minha Constituição, segundo texto do próprio site da organização, "foi criada em 2010 para defender nossa Constituição, ameaçada por leis draconianas do governo que põem em risco as liberdades fundamentais na França". No caso em questão, a associação tem incentivado as mulheres que assim 
surgem também movimentos muitas vezes extremos como a agressão a mulheres pelo uso das vestes proibidas. É importante lembrar que tal fenômeno não é algo restrito ao caso francês: países como a Bélgica, Itália, Dinamarca, Áustria, Holanda e Suíça possuem, ou planejam ter, legislações similares. Além disso, o tema já foi objeto de deliberação no âmbito da Organização das Nações Unidas (ONU), bem como de tribunais internacionais ${ }^{4}$. Tais fatos apenas enfatizam a importância de um amplo debate acerca da matéria, na tentativa de conciliação de interesses antagônicos.

A grande questão é como se coloca tal imposição legal e estatal dentro de um contexto que nos leva a refletir acerca da relação entre direito, democracia e religião em um Estado que se quer secular: quais seriam seus limites dentro de uma sociedade secular? Quais os limites da ação estatal frente à liberdade de seus cidadãos? Como conciliar a liberdade religiosa na pluralidade cultural que hoje se coloca? Como a tensão entre inclusão e exclusão, entre direito à diferença e direito à igualdade se coloca em tais situações? Essas são algumas das questões que permeiam a polêmica, e que o presente artigo pretende abordar.

2. Estado Secular e Modernidade: o locus necessário para o surgimento da igualdade e liberdade

A existência de um Estado secular é uma conquista tipicamente moderna. Sua importância nas sociedades modernas é tal que o processo de secularização esta incluído no próprio conceito de modernidade, como diz Habermas

O conceito de modernização refere-se a um conjunto de processos cumulativos e de reforço mútuo: à formação de capital e mobilização de recursos; ao desenvolvimento das forças produtivas e ao aumento da produtividade do trabalho; ao estabelecimento do poder político centralizado e à formação de identidades nacionais; à expansão dos

queiram a não deixar de usar burca ou niqab apenas pela determinação legal, contribuindo, por exemplo, com o pagamento de eventuais multas. A organização expressamente incentiva a desobediência civil.

$4 \quad$ No Comitê de Direitos Humanos das Nações Unidas (CDH) já se tratou do tema, como no caso Hudoyberganova, no qual uma mulher foi expulsa de uma universidade no Uzbequistão devido ao uso de véu islâmico. Também no Tribunal Europeu de Direitos Humanos se tratou do tema, como nos casos Dahlab contra Suiça, Karaduman contra Turquia, Bulut contra Turquia, Leyla Sahin contra Turquia, entre outros, sendo a maioria deles, como se pôde notar, contra a Turquia. Nesses casos ultimamente citados, discutia-se também, acerca do uso de determinadas vestes islâmicas no âmbito de universidades, seja para a obtenção de diploma ou para validade da identidade estudantil, por exemplo. 
direitos de participação política, das formas urbanas de vida e da formação escolar formal; à secularização de valores e normas, etc (HABERMAS, 2000, p. 5).

Desse modo, pelo processo de secularização, qualquer argumentação a ser feita no ambiente público, ou usando os termos habermasianos, na esfera pública, deve ser feita de modo independente de tradições religiosas ou metafísicas, no sentido de que devem possuir uma racionalidade epistêmica e comunicativa que legitimem a defesa pública de uma posição. Nesse contexto, mediante a concordância majoritária acerca da crucialidade do princípio de liberdade religiosa no sentido de que o Estado, e a sociedade, devem ser tolerantes com todas as religiões pacíficas e também com os que não possuem fé alguma, dois lados se revelam importantes (DWORKIN, 2006, p. 56). Por um lado tem-se a ideia, nos dizeres de Dworkin, de que não basta que uma sociedade religiosa seja tolerante, mas que seja ela uma sociedade secular tolerante (a secular tolerant society e não a religious tolerant society). Tal diferença parece ser irrisória, mas não se trata de um mero jogo de palavras: a distinção entre os dois modelos acaba por refletir o lugar da religião na política e na vida pública de uma nação. Por outro lado, falar em uma sociedade secular não significa dizer que argumentos religiosos devam ser totalmente excluídos do ambiente público, visto que esses podem ser o único meio de expressão de grande parte de uma população que, de outro modo, seriam excluídas do processo democrático. O que se exige, assim, é uma tradução dos argumentos de ordem religiosa, isto é, para que tais argumentos sejam levados da esfera pública informal (ambiente de manifestação de opiniões) para a formal (ambiente de verdadeira deliberação) eles devem ser traduzidos de modo que sejam exprimidos de modo mais neutro e racional possível, facilitando a compreensão, o diálogo e o debate com os que pensam de modo diferente. Tal perspectiva é tratada, muitas vezes sob a ótica mais ampliada da relação entre Direito e Moral, como se pode notar na seguinte reflexão proferida pelo Ministro Marco Aurélio no voto proferido no julgamento da Arguição de Descumprimento de Preceito Fundamental (ADPF) $132^{5}$ :

[...] o Direito sem a moral pode legitimar atrocidades impronunciáveis, como comprovam as Leis de Nuremberg, capitaneadas pelo Partido Nazista, que resultaram na exclusão dos judeus da vida alemã. [...] Por outro lado, o Direito absolutamente submetido à moral prestou serviços à perseguição e à injustiça, como demonstram

\footnotetext{
5 Julgada em maio desse ano, o Supremo Tribunal Federal, na ocasião de tal ADPF, decidiu pelo reconhecimento das uniões estáveis homoafetivas enquanto entidade familiar, e por sua equiparação, quanto a seus efeitos jurídicos, com as uniões heteroafetivas.
} 
episódios da Idade Média, quando uma religião específica capturou o discurso jurídico para se manter hegemônica. Como se sabe, as condenações dos Tribunais da Santa Inquisição eram cumpridas por agentes do próprio Estado [...] a separação entre Direito e moral constitui uma das grandes conquistas do Iluminismo, restaurando-se a racionalidade sobre o discurso jurídico, antes tomado pelo obscurantismo e imiscuído com a moral religiosa.

Assim, pelo processo moderno de secularização, perdem poder, validade e legitimidade as visões tradicionais do mundo que devem agora ser questionadas pelos critérios da racionalidade instrumental. Entretanto, a validade de tais visões não é totalmente nula, como acima evidenciado.

O objetivo de tal mecanismo é a maior legitimidade nas deliberações em um corpo social, que devem se dar de modo a incluir o maior número possível de cidadãos: sendo os destinatários de uma norma também seus autores, o jogo democrático ganha em liberdade e se fortifica como regime político. Prima-se assim, na modernidade (e aqui se encontra outro grande traço distintivo das sociedades modernas), pela igualdade e liberdade subjetiva do corpo social.

A época moderna encontra-se, sobretudo, sob o signo da liberdade subjetiva. Essa realiza-se na sociedade como um espaço, assegurado pelo direito privado, para a persecução dos interesses próprios; no Estado como participação fundamental, em igualdade de direitos, na formação da vontade política; na esfera privada como autonomia e auto-realização éticas e, finalmente, referida a essa esfera privada, na esfera pública como processo de formação que se efetua através da apropriação da cultura tornada reflexiva (HABERMAS, 2000, p. 122).

É no pálio dessa moderna liberdade subjetiva, entre as quais se coloca a liberdade religiosa, que se insere o debate em questão: pode um Estado, em nome da laicidade e do secularismo, interferir em uma expressão cultural-religiosa de modo a proibir determinado costume? Até que ponto tal intervenção é possível, e como pode ela afetar a inclusão democrática igualitária? Por certo que tais direitos não são absolutos ou intocáveis, mas é preciso estabelecer limites para a restrição de tais direitos, vistos que são garantias subjetivas de cada cidadão. Tais dúvidas crescem tendo em vista a diversidade cultural e religiosa da população mundial, e a dificuldade de que essas pluralidades se façam compreender.

3. Igualdade na desigualdade e o aspecto contra-majoritário no reconhecimento de minorias 
"Há muitos de nós, e nós discordamos sobre o justo"6 . É com essa frase que Jeremy Waldron abre um de seus maiores trabalhos, Law and Disagreement e a partir dela o autor desenvolve durante todo o livro argumentos que mostram a pluralidade de nossa sociedade e as divergências que naturalmente emergem desse pluralismo. As discordâncias se colocam não só sobre o conceito de justiça e o que seja o justo, mas também sobre a existência ou não de Deus, o sentido da vida, sobre o que tolerar, o que respeitar, sobre posições políticas.

No mesmo sentido Dworkin afirma que em se tratando de assuntos morais, pessoas diferentes possuem visões diferentes, cada um julgando ser sua opinião a de maior importância (DWORKIN, 2007, p. 82). Torna-se difícil, em meio a tantas diferenças, falar propriamente em um direito substantivo à igualdade:

A sociedade aparece desde o princípio como uma esfera da desigualdade das necessidades, aptidões e habilidades naturais; forma um contexto objetivo cujos imperativos funcionais invadem inevitavelmente as orientações de ações subjetivas. Nessa estrutura e complexidade fracassam todas as tentativas de introduzir na sociedade o princípio cívico da igualdade e de submeter a sociedade à formação democrática da vontade dos produtores associados (HABERMAS, 2000, p. 100).

E é nesse contexto que se afirma um dos papéis do Direito: este deve pretender solucionar tais controvérsias, através da autoridade de princípios que são, eles próprios, também controversos. Entretanto, colocando fim a tais divergências, e orquestrando os interesses contrastantes em um ambiente de 'desacordos' (disagreements), o direito acaba por revelar um traço antidemocrático e nada inclusivo: a solução deve ser aceita, quer concorde, quer não; os sujeitos de direito são obrigados a participar de situações que julgam injustas e indesejáveis. Tal característica é compreensível quando se trata de direito disponíveis ou patrimoniais, mas deve ser repensada nas ocasiões em que as soluções propostas acabam por violar direitos e liberdades individuais.

Nesse tocante é que Dworkin trata da desobediência civil, julgando ser esta um legítimo instrumento democrático, visto que o governo deve tratar a todos com "igual consideração e respeito". Diferenciando-a de atividades criminosas, nas quais há um mero descumprimento da lei por interesses egoísticos, a desobediência civil pode ter lugar nas ocasiões em que as pessoas, enquanto seres individuais e independentes, discordam entre si quanto a questões morais sérias, ou importantes questões políticas, visto que também

6 WALDRON, 2004, p.1; tradução livre. 
discordam sobre o justo, o correto, o moral, o aceitável (nesse sentido, ver WALDRON, p. 1). O autor parte da distinção entre desobediência "por integridade" e "por justiça", e conclui que:

\begin{abstract}
A desobediência civil, em todas as suas várias formas e estratégias, tem uma relação tempestuosa e complexa com o governo da maioria. Ela não rejeita o princípio inteiramente, como poderia fazer um revolucionário radical; os desobedientes civis permanecem democratas no coração. Mas ela exige algum tipo de ressalva ou exceção [...] Refiro-me à exceção admitida pelo poder constitucional dos juízes, de julgar nulo os atos dos representantes da maioria quando, na visão dos juízes, suas decisões infringem os princípio da justiça contidos na Constituição. Esse poder supõe que a a maioria não tem nenhum direito de agir injustamente, de abusar do poder que detém servindo a seus próprios interesses à custa dos direitos de uma minoria (DWORKIN, 2005, p. 163-164).
\end{abstract}

Fala-se, assim, na preocupação de que os procedimentos legislativos, dado seu caráter majoritário se tornem mecanismos de exclusão e invasão nos direitos individuais das minorias; e no papel contra-majoritário das instituições judiciais na preservação de direitos individuais, principalmente no tocante às minorias legislativas.

Aqui, a teoria começa a se aproximar do caso concreto em estudo. Por certo, a população islâmica constitui minoria na sociedade francesa, e leis como a que proíbe o uso de véu ameaçam suas liberdades subjetivas. Ao proibir o uso de tais símbolos religiosos o Estado Constitucional laico acaba por adotar como oficial um discurso religioso, ou, pelo menos antireligioso. Ser secular não é ser avesso a manifestações religiosas, ou à presença de elementos culturais que denotam certa posição religiosa. Como já dito, pela secularização, o Estado Moderno se revela como um corpo político a-religioso em suas questões públicas. A 'areligiosidade' como traço do secularismo moderno garante que diferentes crenças, ou mesmo a ausência de crença, possam conviver mutuamente em uma sociedade plural e igualitária; sendo todas elas, após um processo de tradução que imprimam ao argumento o mínimo de racionalidade, tratadas com igual consideração e respeito.

Tal posição é fortalecida quando resgatado outro marcante traço característico da modernidade: o direito à diferença. Devido às inegáveis desigualdades substantivas, seja pela ótica econômica, cultural, religiosa, diz-se hoje que, o único meio pelo qual se torna possível a afirmação da igualdade é pela liberdade de ser diferente; pelo igual direito de que cada um manifeste, dentro dos limites da liberdade do outro, suas diferenças. E em meio a tantas diferenças não há como alcançar a justiça social sem o devido reconhecimento de tais desigualdades. 
No contexto da globalização e em um universo de pluralidades, a justiça social, conforme traz Nancy Fraser, deve ser vista sob uma ótica bidimensional. Isso significa que, para a persecução do justo, não basta a resdistribuição, mas se faz igualmente necessário o reconhecimento; somente pela conjunção das duas dimensões é que se atinge a compreensão plena de um corpo social. Falar em reconhecimento significa dizer que não deve haver hierarquias substanciais e muitas vezes institucionalizadas entre os diversos corpos morais na sociedade. Um corpo cultural majoritário não deve se sobrepor aos demais, mas deve ser garantido a todos eles um igual reconhecimento, no sentido de que cada um deles possa expressar, com liberdade, suas identidades. Requer-se, assim, uma política de reconhecimento. Assim, a titularização de direitos subjetivos e fundamentais por todos os cidadãos, não se coloca como uma proposta de uma justiça distributiva, mas resulta do mútuo reconhecimento entre os membros da sociedade, que se reconhecem, todos, como merecedores de igual consideração e respeito ${ }^{7}$, independentemente de raça, sexo, religião ou cultura. Afirma-se, desse modo, uma concepção não individualista das liberdades individuais, isto é, "o indivíduo está capacitado para o desenvolvimento da autonomia apenas na medida em que entretém relações com outros sujeitos, as quais possibilitem com sua forma o reconhecimento recíproco de personalidades individuais" (HONNETH, p. 6). A igualdade não é uma característica inata dos seres humanos: nascemos todos diferentes, e só somos dados por iguais ao nascer em um corpo social que se denomina isonômico. A igualdade é, assim, fruto de uma organização humana; tornamos iguais enquanto membros de um grupo que deve respeitar, igualmente, a diferença entre seus membros: é fundamental que, mesmo na igualdade, nossas diferenças sejam preservadas.

A exclusão de tais diferenças, ou mesmo sua tentativa, pode trazer diversos problemas ao corpo político:

O fato é que, sem a universalidade da cidadania, isto é, sem a inclusão generalizada de indivíduos e grupos [...], as diferenças étnicas e culturais degeneram em conflitos destrutivos entre os diversos grupos. Ou seja, o fato empírico do multiculturalismo mesmo exige uma concepção de justiça e de cidadania que seja universalmente sensível à diferença. $\mathrm{O}$ universalismo da justiça como igualdade, que pressupõe o universalismo da cidadania como inclusão generalizada no sistema jurídico-político, apresenta-se, então, como um universalismo relativo, que exige o respeito recíproco às diferenças (NEVES, 2001, p. 341-342).

7 HONNETH, Justiça e Liberdade Comunicativa. 
Exige-se, nesse contexto, uma inclusão igualitária dos distintos interesses, valores e identidades étnicas e culturais no ambiente público, o que implica que nenhuma dessas identidades, por ser maioria no corpo político e decisório, tenha sequer a pretensão de se sobrepor às demais, muito menos excluí-las.

O problema é que no desenvolvimento de um dado corpo político, de tal "sistema jurídico-político", e isso se verifica desde a Grécia antiga, tem-se procurado garantir a igualdade no ambiente de esfera pública pela eliminação das diferenças, ficando estas restritas à respectiva esfera privada de cada cidadão. Assim, historicamente, toda nossa vida política tem se baseado nessa premissa de que podemos produzir igualdade e que podemos atuar igualitariamente no ambiente público, deixando nossas diferenças e particularidades enclausuradas em nossa vida privada. É o que diz Hannah Arendt em Origens do totalitarismo:

\begin{abstract}
A razão pela qual comunidades políticas altamente desenvolvidas, como as antigas cidades-Estados ou os modernos Estados-nações, tão freqüentemente insistem na homogeneidade étnica é que esperam eliminar, tanto quanto possível, essas distinções e diferenciações naturais e onipresentes que, por si mesmas, despertam silencioso ódio, desconfiança e discriminação, porque mostram com impertinente clareza aquelas esferas onde o homem não pode atuar e mudar à vontade, isto é, os limites do artifício humano. O "estranho" é um símbolo assustador pelo fato da diferença em si, da individualidade em si, e evoca essa esfera onde o homem não pode atuar nem mudar e na qual tem, portanto, uma definida tendência a destruir. [...] Sem dúvida, onde quer que a vida pública e a sua lei da igualdade se imponham completamente, onde quer que uma civilização consiga eliminar ou reduzir ao mínimo o escuro pano de fundo das diferenças, o seu fim será a completa petrificação; será punida, por assim dizer, por haver esquecido que o homem é apenas o senhor, e não o criador do mundo (ARENDT, 1998, p. 335).
\end{abstract}

Pois bem, políticas públicas tais como a que é objeto do presente estudo costumam ser justificadas pela inserção de grupos minoritários no seio do restante da sociedade, afirmando desse modo a igualdade para todos, não importando os valores, crenças e costumes pessoais ou de um determinada coletividade interna à sociedade. Entretanto tais justificativas não se fazem válidas quando a ação defendida invade nitidamente os direitos e liberdades alheios. As ações estatais devem se dar no sentido de garantir e fortalecer, pelo reconhecimento das diferenças, a esfera das liberdades individuais a ponto de se poder dizer que "a liberdade pessoal do indivíduo foi em tal medida assegurada e promovida que estariam à sua disposição esferas de auto-realização nas quais ele pode obter, através do reconhecimento recíproco, um poder de ação muito maior” (HONNETH, p. 9). 
Considerando que diversas culturas e realidades sociais se encontram presentes em nossa sociedade e que tais múltiplas identidades devam ser respeitadas igualmente, restrições à manifestação de uma dada identidade, seja de um grupo étnico, religiosos ou cultural, se mostra injustificável.

\section{Conclusão}

A democracia nasce por meio de uma concepção individualista do corpo social, isto $e$, pressupõe-se que, de forma oposta a uma visão orgânica ou holística segundo a qual o todo precede as partes, considera que a sociedade política, ou qualquer forma de sociedade em um modo mais geral, nasce como resultado da vontade dos indivíduos, como um produto artificial, um construto humano. Parte-se da ideia de que os indivíduos são soberanos e que são estes os protagonistas dentro de um jogo democrático. Entretanto, no desenvolver dos corpos democráticos, foi o oposto que se mostrou acontecer: os diversos grupos internos à sociedade (sejam eles associações, partidos, sindicatos, entre outros) acabaram por se mostrar mais politicamente proeminentes do que os indivíduos em sim, isolados. "Os grupos e não os indivíduos são os protagonistas da vida política numa sociedade democrática, na qual não existe mais um soberano, o povo ou a nação, composto por indivíduos que adquiram o direito de participar direta ou indiretamente do governo, na qual não existe mais o povo como unidade ideal (ou mística), mas apenas o povo dividido de fato em grupos contrapostos e concorrentes, com a sua relativa autonomia diante do governo central (autonomia que os indivíduos singulares perderam ou só tiveram num modelo ideal de governo democrático sempre desmentido pelos fatos)" (BOBBIO, 1986, p. 23).

A democracia não pode ser vista, e isso já é claro na teoria política, simplesmente como um governo da maioria. Foi graças a tal visão que regimes 'democráticos' se mostraram terríveis à história da humanidade, e se revelaram verdadeiros regimes totalitários, tais como o fascismo e o nazismo. Conforme preconizado pela grande maioria da doutrina dos direitos humanos, e até mesmo positivado em diversas Constituições mundo afora (como no inciso III do art. $1^{\circ}$ da Constituição Federal brasileira) há de se levar em conta na modelação de uma democracia a dignidade da pessoa humana. Zelar por tal dignidade é garantir os direitos fundamentais, a igualdade substancial, o direito à diferença, as liberdades subjetivas não só da maioria do corpo democrático, mas também dos grupos minoritários, que constantemente demandam por seu efetivo reconhecimento. 
A proibição do uso de burca e niqab em ambientes públicos exclui a legítima manifestação cultural de uma minoria religiosa: os islâmicos. Tal atitude é, na verdade, excludente e tendente à eliminação de uma diferença; e tal exclusão é contrária à concepção moderna de democracia e secularismo. A luta pela não proibição expressa, inclusive pela desobediência civil, denota a demanda de uma minoria inserida em um corpo democrático pela defesa de sua liberdade religiosa: pela proibição o Estado interfere em esferas tipicamente subjetivas e indisponíveis, contribuindo para a redução do pluralismo social.

A eliminação das diferenças tende a produzir na população uma massa indistinta e petrificada, e foi desse modo que grande parte dos regimes totalitários que conhecemos começou. A preservação das diferenças e da diversidade no corpo social é requisito para a existência de uma democracia forte, saudável e inclusiva; que em seus debates e deliberações inclua diferentes óticas e opiniões.

O véu é visto pela mulher muçulmana como uma demonstração de respeito a Deus e ao islamismo, e não como uma subordinação ao homem, ou a uma negação de sua identidade. $\mathrm{O}$ veto a seu uso corresponde, na verdade, um desrespeito a uma certa identidade cultural e religiosa, significa a exclusão oficial, isto é, por meio de atos governamentais, de um grupo social da comunidade; e constitui uma violação à legislação de direitos humanos, às liberdades pessoais e à liberdade religiosa.

Não faz sentido um governo da maioria para a maioria, pois a ideia de vontade geral do povo é inalcançável: não se pode determinar quem é o povo, e muito menos sua vontade geral, uma vez que coabitam, no corpo social, diversos, plurais e infindáveis interesses. A democracia, na modernidade deve, pela manutenção das diferenças, buscar ser um governo de todos: não se trata de ratificar um jargão, mas de uma defesa da busca ininterrupta pela inclusão: pela inclusão do outro; inclusão do diferente.

Em meio a tanto pluralismo e diversidade, se desenvolveu em nossa sociedade uma certa "injustiça estrutural" para com os grupos minoritários, como os islâmicos, revelando atos de exclusão social e de intolerância, e muitas vezes desprezo, para com o diferente. Nessa perspectiva o Estado Democrático de Direito ainda é o melhor, e talvez o único, modo pelo qual sejam garantidos os direitos de tais minorias. Nesse sentido, importante papel tem o judiciário com seu traço contra-majoritário, visto que os cargos em tal poder não são ocupados por vias eleitorais, imprimindo, pelo menos em tese, maior liberdade à atividade jurisdicional. O desenvolvimento, dentro do Estado democrático de Direito, de um modelo jurídico e político capaz de se adequar a diferentes contextos e a distintas realidades étnicas, 
culturais, regionais e religiosas contribuirá para uma maior justiça social, e para uma maior reconhecimento efetivo de camadas da população que, a priori, se encontram excluídas em muitas das esferas sociais.

O princípio da igualdade não pode ter a pretensão de estabelecer na sociedade uma igualdade de fato, ou uma homogeinização social ou cultural, mas deve, ao contrário, pressupor tais desigualdades fáticas e uma grande heterogeneidade de valores, crenças e interesses. Uma das problemáticas do princípio da igualdade é que ele só pode ser formulado quando estiver inserida em sua estrutura a noção da desigualdade. Essa é a releitura que se deve fazer hodiernamente a tal clássico princípio.

Torna-se imprescindível a ideia de que no ambiente público haja um respeito recíproco e simétrico às diferenças, e que os direitos e garantias individuais acompanhem tal ideia, se mostrando sensíveis ao convívio simultâneo e inclusivo dos diferentes, possibilitando para estes um tratamento jurídico igualitário. Assim, o direito à diferença deve ser considerado como um pressuposto para a institucionalização jurídica e política da igualdade.

\section{Referências Bibliográficas}

ARENDT, H. Origens do Totalitarismo, tradução de Roberto Raposo. São Paulo; Companhia das Letras, 1998.

BOBBIO, N. O futuro da democracia; uma defesa das regas do jogo, traduzido por Marco Aurélio Nogueira. Rio de janeiro, Paz e Terra, 1986.

DWORKIN, R. Is democracy possible here? Princeton University Press, 2006, p. 52-89.

. O império do direito. 2. ed. São Paulo; Martins Fontes, 2007.

Fontes, 2005.

Uma questão de princípio; tradução de Luís Carlos Borges. São Paulo, Martins

FRASER, N. A justiça social na globalização; tradução de Teresa Tavares. Conferência apresentada colóquio "Globalização: Fatalidade ou Utopia?" (22-23 de Fevereiro de 2002), organizado em Coimbra pelo Centro de Estudos Sociais. Disponível em <http://www.eurozine.com/pdf/2003-01-24-fraser-pt.pdf>. Acesso em 5 mai. 2009.

FREITAG, B. Habermas e a Teoria da Modernidade. In Caderno CRH, n. 22, p. 138-163. Salvador, jan./jun. 1995. 
HABERMAS, J. O Discurso Filosófico da Modernidade: doze lições; tradução de Luiz Sérgio Repa e Rodnei Nascimento. São Paulo, Martins Fontes, 2000.

. Teoría de la acción comunicativa: racionalidade de la acción y racionalización social, versión castellana de Manuel Jimenez Redondo. Madrid, Taurus, 2003.

108-155.

. Entre naturalismo y religion; tradução de Pere Fabra et al. Barcelona, Paidós, p.

HONNETH, A. Justiça e liberdade comunicativa: reflexões em conexão com Hegel; tradução para fins acadêmicos de Fernando Alves Gonçalves. Não publicado.

NEMOIANU, V. The Church and the secular establishment: a philosophical dialog between Joseph Ratzinger and Jürgen Habermas. In Logos, Oxford, v.9, n.2, abr./jun. 2006, p. 17-42.

NEVES, M. Justiça e diferença numa sociedade global complexa, in SOUZA, Jessé (organizador). Democracia hoje: novos desafios para a teoria democrática contemporânea. Brasília, Editora UnB, 2001.

ROSENFELD, M. A identidade do sujeito constitucional, tradução de Menelick de Carvalho Netto. Belo Horizonte, Mandamentos, 2003.

ROULAND, N. Nos confins do Direito: antropologia jurídica da modernidade; tradução de Maria Ermantina de Almeida Prado Galvão. São Paulo; Martins Fontes, 2008.

WALDRON, J. Law and Disagreement. Oxford: Oxford University Press, 2004. 